\title{
Evaluation of Tick-Bite Cases with Infection Agents among Patients Visiting State Hospital in Malatya, Turkey
}

\author{
Ülkü Karaman ${ }^{1}$, Neval Berrin Arserim², Pınar Yücefırat ${ }^{3}$, Ali Beytur ${ }^{4}$, İlhan Geçit ${ }^{4}$, Erdal Karcı ${ }^{5}$, Mesut \\ Karadan $^{5}$
}

Received: 09 February 2015 accepted: 10 April 2015/ published online: 17 April 2015

(C) Ordu University Institute of Health Science, Turkey, 2015

\begin{abstract}
Objective: The study aims to determine where the patients who applied to the state hospital with tickbites between April 2009-December 2011 to evaluate bitten areas of the body and species separation that forms infestation and the cases in terms of bacterial and viral infection.

Methods: The patients having tick-bites applied to the state hospital to form the material of the study. Anamnesis was taken from the patients applied to the hospital. It was recorded that where the patients came from and where the infestation was.
\end{abstract}

1 Ordu University Faculty of Medicine Department of Parasitology, Ordu, Turkey

2 Dicle University Faculty of Veterinary Medicine,

Diyarbakır, Turkey

3 Malatya State Hospital Infectious Diseases Clinic, Malatya, Turkey

4 Malatya State Hospital Department of Urology, Malatya, Turkey

5 Malatya State Hospital Laboratory of Parasitology,

Malatya, Turkey

Address for correspondence/reprints:

Ülkü Karaman, PhD.

Email: ulkukaraman@yahoo.com

The study was presented as a poster at 16th National Congress of Parasitology which held on between 1th-7th November 2009, in Adana/Turkey.

DOI: $10.19127 / \mathrm{mbsjohs.85470}$
Results: Patients' serological test results were found within normal levels. Tick type found as 69 Hyalomma marginatum, 29 Rhipicephalus bursa, 27 Hyalomma anatolicum anatolicum, 21 Hyalomma aegyptium, 19 Hyalomma anatolicum excavatum, 12 Rhipicephalus sanguineus, 9 Dermacentor marginatus, 7 Haemaphysalis parva, and 4 Hyalomma detritum. Also it was determined that there were 3 larvas and 5 nimfs belonged to Hyalomma species in a growth phase and 1 nimf belonged to Haemaphysalis.

Conclusion: In the study it was concluded that the $H$. marginatum, known as Crimean-Congo Hemorrhagic Fever (CCHF) vector, is more common than the other types and it is a risky situation for the city to be geographically near to the regions where the virus is seen, thus some precautions should be taken.

Key words: Tick, Malatya, bacterial infection, viral infection

\section{Introduction}

The ticks spreading to all regions around the world are bloodsucker arthropods and the species that are belong to Ixodidae family are important in transmitting the infection agents to humans. These are active especially between spring and autumn (Karaer et al., 1984;Gargili, 2009). 
Ticks have to suck blood in each growth phase throughout their life (larvae-nymph-mature) and females suck blood more than males (Karaer et al., 1984; Gargili, 2009).

The diseases in which ticks are vectors are indirectly important because of their damages in the animals that are economically important, and also they are directly important because of the high mortality infections they cause in humans. Ticks are the vectors of bacterial (tularemia, Lyme disease), rickettsia (spotted fever, Q fever, ehrlichiosis), parasitic (babesiosis) and viral (tick borne encephalitis, hemorrhagic fevers) infection agents among zoonotic agents (Karaer et al., 1984; Despommier et al., 2000; Gargili, 2009).

Vector ticks, in a growth phase, can convey disease agent taken from the infected host to the new host where they sucked blood in the next growth phase (Sparagano et al, 1999). Most of the disease agents are also passed to infected ticks' eggs so they are conveyed to the new generations and this provides disease agents to spread between tick populations (Jongejan and Uilenberg, 2004). Ticks of the same type, as being the vector, can carry more than one cause of disease too (viral, parasite, bacterial) (Sparagano and Jongejan, 1999).

The study aim was to determine where the patients who applied to the state hospital with tickbites between April 2009 and December 2011 to evaluate bitten areas of the body and species separation that forms infestation and the cases in terms of bacterial and viral infection.

\section{Materials and Methods}

\section{The collection of samples}

The patients having tick-bites applied to the state hospital to form the material of the study between April 2009 and December 2011. Anamnesis was taken from the patients applied to the hospital. It was recorded that where the patients came from and where the infestation was.

\section{Microbiological, Biochemical and Hematologic Tests}

The cases were monitored in terms of bacterial (Brucellosis, Salmonellosis, Q fever) and viral infections (CCHF). In the blood samples taken for viral infection (CCHF), complete blood cell count with full blood count, prothrombin time (PTZ, INR) values and biochemical parameters such as Alanine Transaminase (ALT), Aspartate Aminotransferase (AST), Gama-GlutamilTransferase (GGT), Lactate Dehydrogenase (LDH) and Creatine Kinase (CK) were followed. Serums of the taken blood were separated to be evaluated in terms of bacterial and they were kept until it worked in $-20^{\circ} \mathrm{C}$. They were sent to Dicle University Medical Faculty Department of Microbiology appropriately for cold chain procedure.

In the serums collected from patients Rose Bengal agglutination test (Seromed) for Brucellosis and Salmonellosis (O and $\mathrm{H}$ antigens) Salmonella lam agglutination test (TYDAL Belgium) were used.

Automatic Elisa device (DSX, Dynex Tecnologies) was used for Q fever. Therefore, IgG antibodies (Virion/Serion, Germany) were studied against Coxiella burnetii phase II antigens.

\section{The diagnosis of the tick}

The all collected ticks were put in glass covered tubes that included 70\% Alcohol -Glycerin and kept in Parasitology Laboratory until they were examined. The species separation of the ticks was done according to the diagnostic key by the help of stereomicroscope. Afterwards the ticks were taken into the glass covered tubes again and they were kept

\section{Results}

The average age of the 210 patients applied with the complaints of tick-bites was $24.65 \pm 2.07$. Tick bites areas and numbers were determined as 37 penis, 29 breast, 27 pubic, 22 back, 18 foot and leg, 18 hip, 17 neck-head-nape of the neck, 15 arm and arm pit, 12 ear and 11 abdomen. Also, it was stated that 4 of the ticks brought to Parasitology Laboratory were caught while they were perambulating on the human body and 27 ticks were found in their houses and brought by locals. 
It was found out that 69 of the ticks that were diagnosed according to their species were $H$. marginatum (Figure 1, Figure 2a,2b), 29 of them were $R$. bursa, 27 of them were H. a. anatolicum (Figure 3), 21 of them were H. aegyptium (Figure 4), 19 of them were H. a. excavatum (Figure 5), 12 of them were $R$. sanguineus (Figure 6), 9 of them were D. marginatus (Figure 7), 7 of them were $H$. parva (Figure 8) and 4 of them were $H$. detritum. Also it was determined that there were 3 larvas and 5 nimfs belonged to Hyalomma species in a growth phase and 1 nimf belonged to Haemaphysalis. Moreover 4 of the ticks were $O$. lahorensis from Argasid ticks. O. lahorensis ticks were seen while they were perambulating on the patient's body.

It was also found out that 7 of the ticks that were found in their houses and brought to the laboratory by the locals were $H$. parva, 10 of them were $H$. anatolicum and 10 of them were $H$. aegyptium.

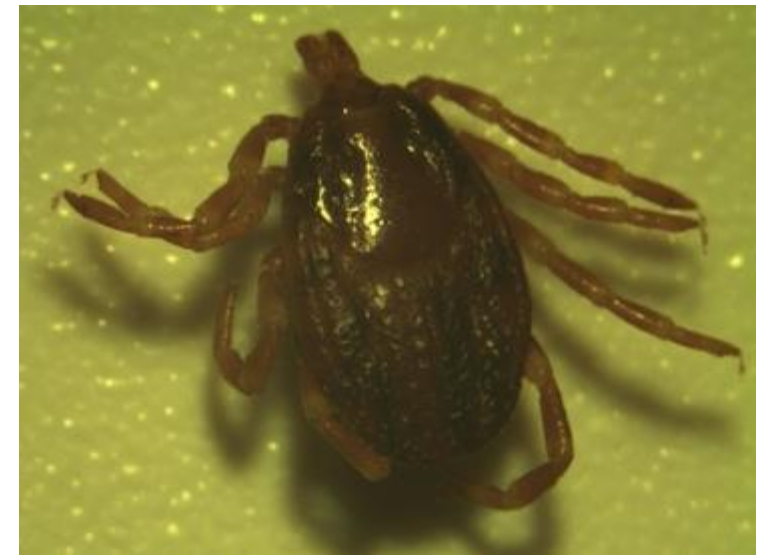

Figure 1: Hyalomma marginatum female

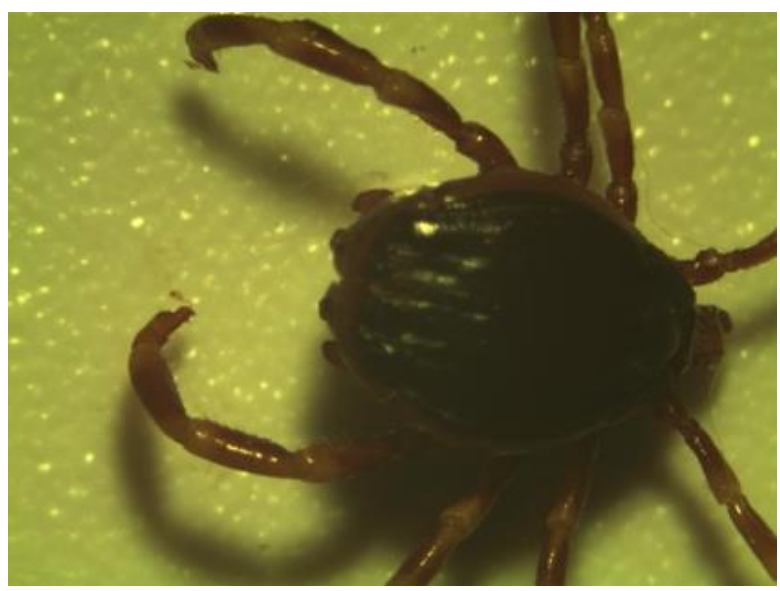

Figure 2a: Hyalomma marginatum

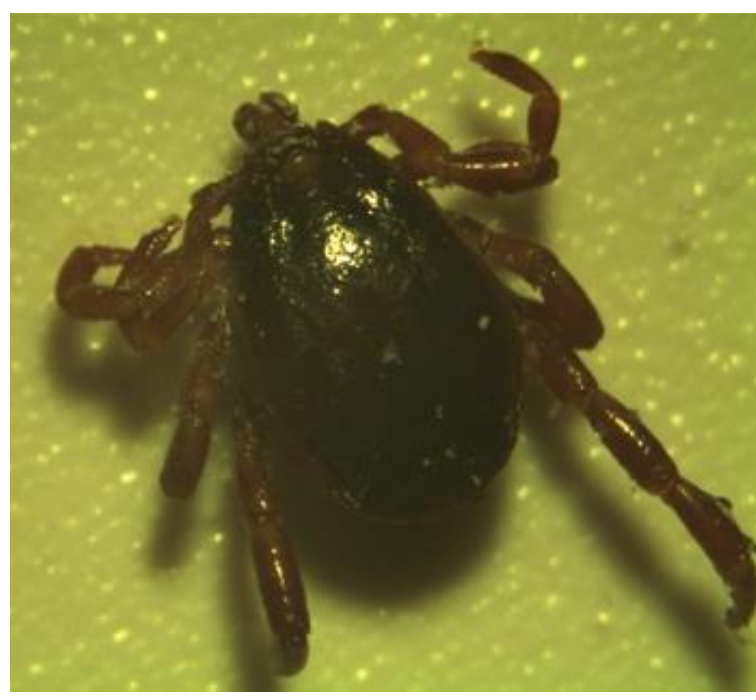

Figure 2b: Hyalomma marginatum

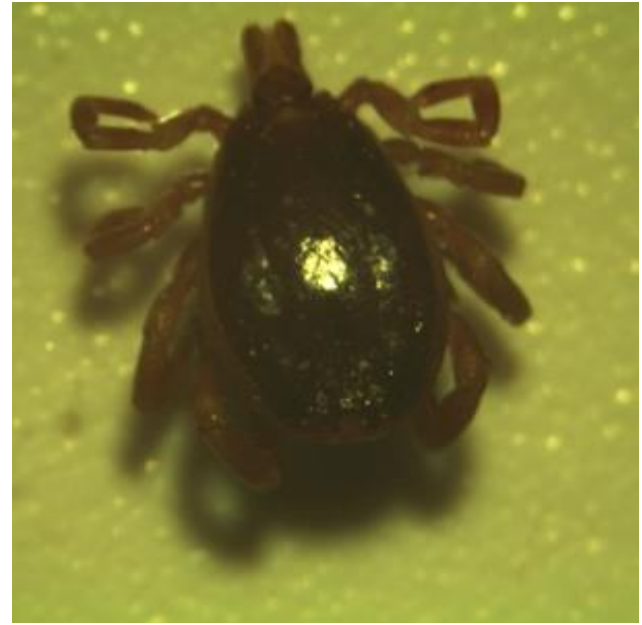

Figure 3: Hyalomma anatolicum anatolicum male

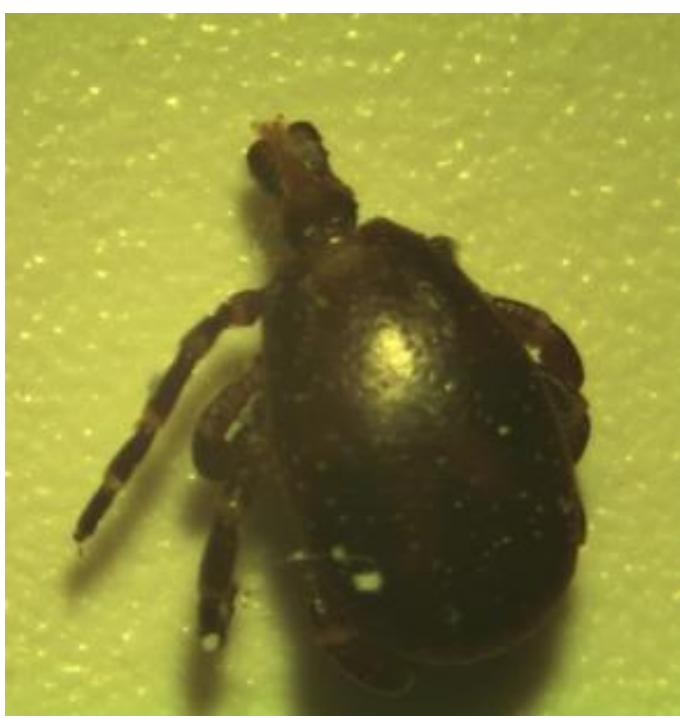

Figure 4: Hyalomma aegyptium male 


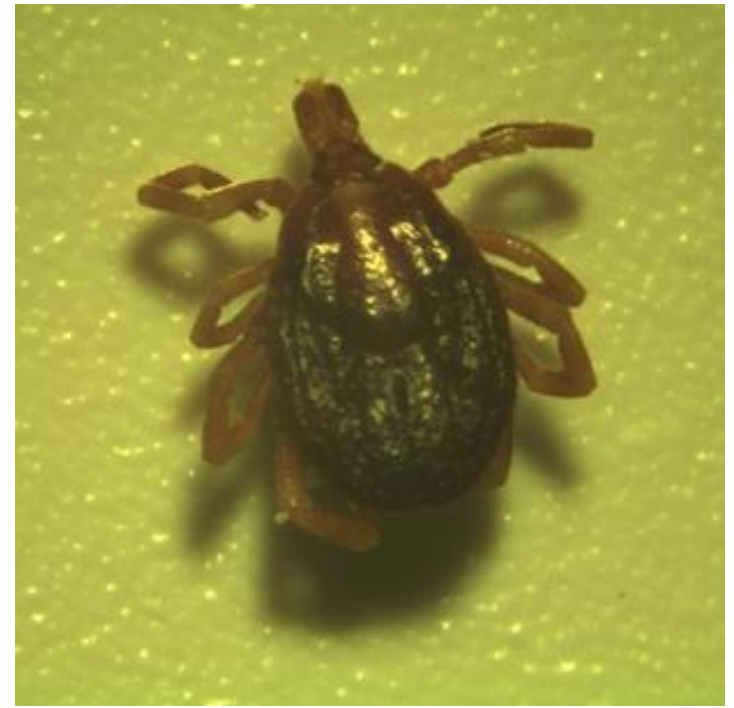

Figure 5: Hyalomma anatolicum excavatum female

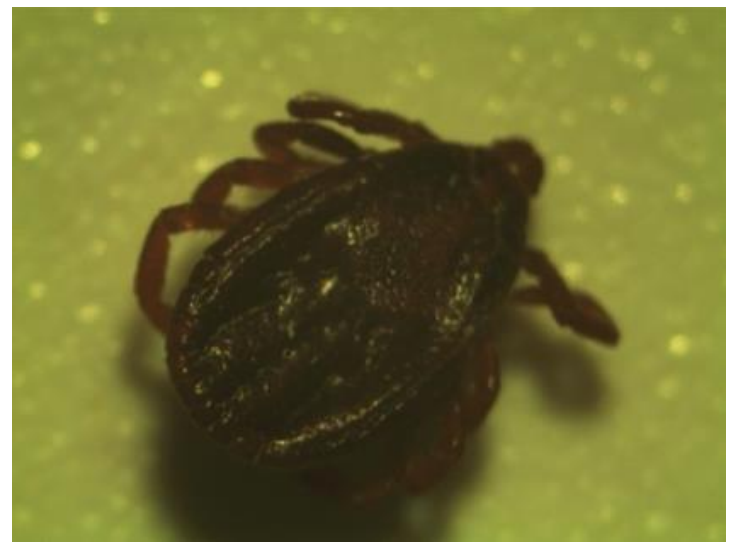

Figure 6: Rhipicephalus sanguineus female

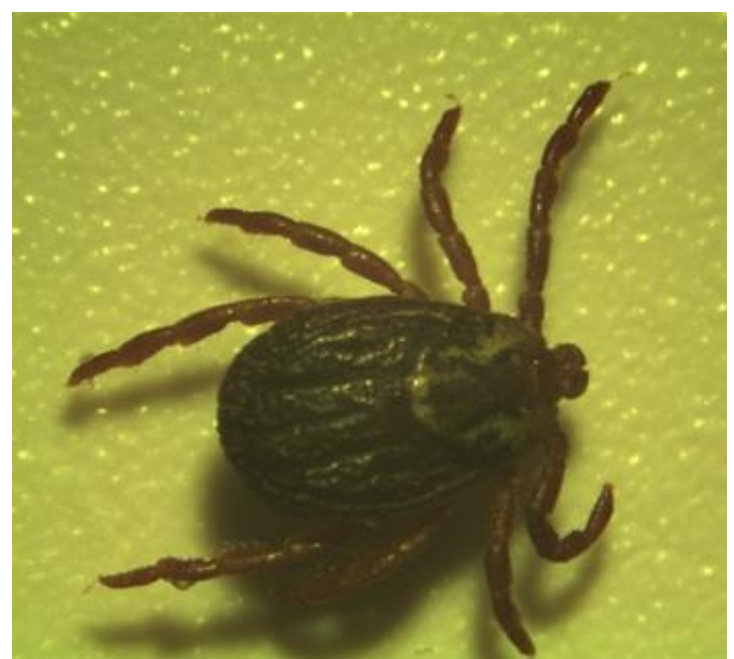

Figure 7: Dermacentor marginatus female

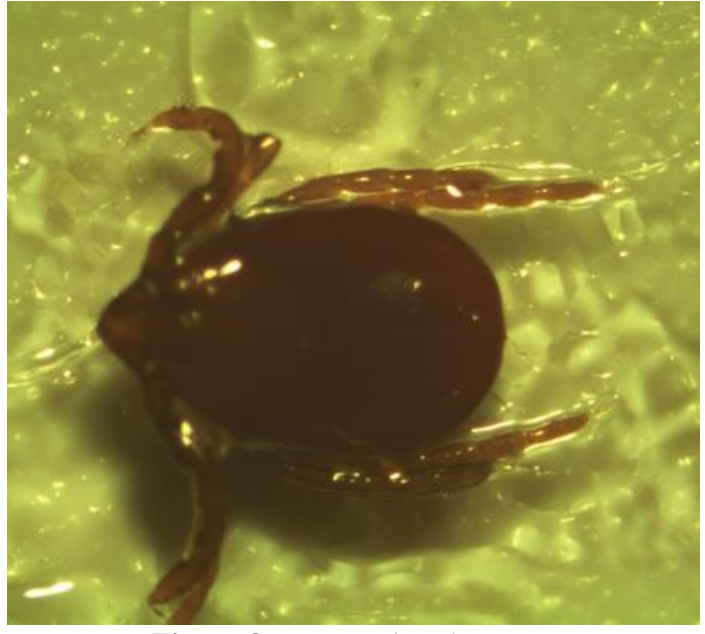

Figure 8: Haemaphysalis parva

All of the serums in the serologic tests were found negative in terms of Salmonella, Brucella and Q fever.

\section{Discussion}

The ticks spreading to all regions around the world are bloodsucker arthropods which transmit several infections including viral, protozoan, bacterial (e.g. Lyme disease) and rickettsia infection agents (e.g. detrital fever, Ehrlichiosis, Q fever, and Tularemia etc.). Major vectors of the tick-originated infections belong to Ixodidae family and it has been detected that $H$. marginatum type of ticks in Turkey are Crimean-Congo Hemorrhagic Fever (CCHF) vector (Karaer et al., 1984; Despommier et al., 2000; Gargili, 2009). In order to control the tick population, detecting their types and distribution will play an important role in planning the most effective and long lasting methods to fight with them.

In the phenomenon's applying to Emergency Service in Turkey, the distribution of the cases diagnosed as CCHF by year are as following: 150 in the years 2002-2003, 249 in 2004, 266 in 2005, 438 in 2006, 717 in 2007 and 1315 in 2008. Mortality rates were 0 in 2002, 6 in 2003, 13 in 2004, 13 in 2005, 27 in 2006, 33 in 2007 and 63 in 2008 (Ergonul, 2006; Kara, 2008; Taskesen et al., 2008; Yilmaz et al., 2009). Also Sumer (Sumer, 2010) stated that 168 tick-bite phenomenons applied to the Emergency Service of Kaş State Hospital between July 2007 and February 2009 (Sumer, 2010). In the study, 210 tick-bites that applied to the hospital between March-November 2009 were determined and in the follow-up of the phenomenons no infection was discovered. 
It was notified that ticks were often found on the skin with hair, in the back part of the ear and on femur region (Edlow and McGillicuddy, 2008). Similar to that, Taşkesen and his friends declared that the most common the localization was on legs (37\%), and on corpus (21\%). As for $\mathrm{Al}$ and his friends (Al et al., 2008) tick localization was on head-shoulder and on legs, while Sümer (Sumer, 2010) discovered the ticks mainly on legs (34.52\%), on corpus (11.9\%) and on auxiliary region $(8.34 \%)$. Parallel to that, in the study, It has been confirmed that 37 of bites on penis, 29 of bites on breast, 27 of bites on pubic, 22 of bites on back, 18 of bites on foot and leg, 18 of bites on hip, 17 of bites on neck-head-nape of the neck, 15 of bites on arm and arm pit, 12 of bites on ear and 11 of bites on abdomen.

Many types, which are connected to the species as Ixodes, Boophilus, Dermacentor, Amblyomma, Hyalomma and Rhipicephalus, have been reported as vectors (Sparagano et al., 1999). In the studies carried out on tick epidemiology, 32 types, 22 of which are found commonly and 15 of which have been encountered in each of our geographical regions, have been detected (Karaer et al., 1997; Sayin et al., 1997). Crimean-Congo Hemorrhagic Fever has the largest area to spread in the diseases infected by ticks and affects the countries hosting Hyalomma species (Hoogstraal, 1979; Ergonul, 2006). The most important way of contamination is the blood absorption by infected ticks (Whitehouse, 2004). There have been reports stating that the virus can reside and reproduce in ticks lifelong (1-1.5 years) and for generations (transovarial + transstadial transfer) (Sayin et al., 1997).

It was stated that Amblyomma variegatum, $H$. marginatum, $H$. m. rufipes, $H$. a. anatolicum, $H$. $a$. asiaticum, $H$. truncatum, $H$. impeltatum, $D$. marginatus, $R$. evertsi, $R$. rossicus species have the real vector capacity nowadays and especially Hyalomma species play an active role in CCHF epidemics (Hoogstraal, 1979). In our country, the existence of the virus has been discovered in the reboring flourishing periods of $H$. marginatum and in the eggs of females (Estrada-Pena et al., 2007; Vatansever et al., 2007). Besides this species which has been proved to be a vector, $\mathrm{CCHF}$ virus has been detected in Boophilus annulatus, $R$. bursa, D. marginatus tick species, too. However, the role of these species as vectors hasn't been proved (Kondratenko, 1976; Hoogstraal, 1979).
In the studies carried out in our country about the spread of CCHF virus in ticks, CCHF virus has been detected in $H$. marginatum, $H$. detritum, $R$. bursa and B. annulatus species (Gargili, 2009).

In the resource data no research that categorizes ticks in Malatya region on a basis of species has been encountered. Ticks, which were studied in the research as well, have been determined according to their species as $69 \mathrm{H}$. marginatum, $29 \mathrm{R}$. bursa, $27 \mathrm{H}$. a. anatolicum, $21 \mathrm{H}$. aegyptium, $19 \mathrm{H}$. a. excavatum, $12 R$. sanguineus, 9 D. marginatus, 7 $H$. parva, and $4 H$. detritum. Also it was determined that there were 3 larvas and 5 nimfs belonged to Hyalomma species in a growth phase and 1 nimf belonged to Haemaphysalis. Moreover 4 of the ticks were $O$. lahorensis from Argasid ticks. In the study, $H$. marginatum, which has been proved to be a vector, and also $H$. detritum, $R$. bursa and D. marginatus, which have been reported to carry CCHF, have been detected. The ticks that have been determined can be a vector for $\mathrm{CCHF}$ and a lot of bacterial, parasitic and viral factors with Salmonellosis Brucellosis and Q fever working serologically. It was thought that interpreting the stated diseases and tick infestations together will be more important in terms of following infections epidemiologically.

In the study; because of the fact that $H$. marginatum, which is known as a CCHF virus vector, outnumbers the other species and the city is geographically close to the area, in which this virus has been seen, the city was considered as a critical area and it was concluded that protective precautions were necessary. Under these circumstances it was suggested that public health education should be given on protection from the bacterial, viral and parasitic diseases.

Informed Consent: Written informed consent was obtained from patients who participated in this study.

Peer-review: Externally peer-reviewed.

Author Contributions: Concept - UK, AB, IG.; Design UK, AO; Supervision AÖ,AB; Materials UK, PY, AB, İG, MK, EK; Data Collection and/or Processing - UK, PY, AB, İG, MK, EK; Analysis and/or Interpretation - UK, NBA, AO; Literature Review - UK, NBA; Writing - UK; Critical Review - PY, AB, IG, AO, NBA

Conflict of Interest: No conflict of interest was declared by the authors.

Financial Disclosure: The authors declared that this study hasn't received no financial support. 


\section{References}

Al B, Yildırim C, Söğüt Ö, Yesilkaya A. The evaluation of 39 tick bites applied to Batman State Hospital Emergency Service in seven months. Akademik Acil Tip Derg, 2008; 7: 4043.

Despommier DD, Gwadz RW, Hotez PJ, Knirsch CA. Parasitic diseases, 4. ed., Apple Trees Prod, New York. 2000

Edlow JA, Mc Gillicuddy DC. Tick paralysis. Infect Dis Clin North Am, 2008; 22: 397-413.

Ergonul O. Crimean-Congo hemorrhagic fever. Lancet Infect Dis, 2006; 6: 203-214.

Estrada-Pena A, Vatansever Z, Gargili A, Aktas M, Uzun R, Ergonul O, Jongejan F. Modeling the spatial distribution of Crimean-Congo hemorrhagic fever outbreaks in Turkey. VectorBorne Zoonotic Dis, 2007; 7: 667-78.

Gargili A. Ticks as a vector and the condition in Turkey. ANKEM Derg, 2009; 23: 249-252.

Hoogstraal $\mathrm{H}$. The epidemiology of tick-borne Crimean-Congo hemorrhagic fever in Asia, Europe, and Africa. J Med Entomol, 1979; 15: 307-417.

Jongejan F, Uilenberg G. The global importance of ticks. Parasitology, 2004; 129: 3-14.

Kara A. Removing Ticks. Çocuk Sağ ve Has Derg, 2008; 51: 117-122.

Karaer Z, Yukari BA, Aydin L. The ticks in Turkey and ticks as vectors, In: Özcel MA, Daldal N (eds): Arthropod diseases in Parasitology and vectors, $\mathrm{T}$ Parasitol Dern Izmir, Turkey. ed: 13. 1997; 363-434,

Kondratenko VF. Importance of ixodid ticks in the transmission and preservation of the causative agent of Crimean hemorrhagic fever in foci of the infection. Parasitologia, 1976; 10 (4): 297302.

Sayin F, Dincer S, Karaer Z, et al. Status of tick infestation of sheep and goats in Turkey. Parasitologia, 1997; 39: 145-52.
Sparagano O, Allsop MT, Mank RA, Rijpkema SG, Figuerova JV, Jongejan F. Molecular detection of pathogen DNA in ticks (Acari:Ixodidae): a review Exp Appl Acarol, 1999; 23: 929-60.

Sparagano O, Jongejan F. Molecular characterization of ticks and tick borne pathogens. Parasitologia, 1999; 41: 101-5.

Sümer A. The evaluation of the patients applied to Kaş State Hospital Emergency Service due to tick bites. Kafkas Univ Vet Fak Derg, 2010; 16: 49-53.

Taşkesen M, Okur N, Taş M.A. The evaluation of 19 cases applied due to tick-bites Dicle Tip Derg, 2008; 35: 110-113.

Vatansever Z, Midilli K, Deniz A, Ergin S, Alp H, Gargili A. The vector of Crimean-Congo Haemorrhagic Fever: Hyalomma $\mathrm{m}$. marginatum. $15^{\text {th }}$ National Parasitology Conference Abstract Book KayseriUrgup,Turkey. 2007; 257

Whitehouse CA. Crimean-Congo hemorrhagic fever. Antiviral Res, 2004 ; 64: 145-60.

Yilmaz GR, Buzgan T, Torunoglu MA, et al. A preliminary report on Crimean-Congo hemorrhagic fever in Turkey. Euro Surveill, 2008; 33: 18953.

Yilmaz RG, Buzgan T, Irmak H, Safran A, Uzun R, Cevik MA, Torunoglu MA. The epidemiology of Crimean-Congo hemorrhagic fever in Turkey, 2002-2007. Int J Infect Dis, 2009; 3: 380-386. 